\title{
Intensive surveillance endoscopy for multiple gastrointestinal tumors in a patient with constitutional mismatch repair deficiency: case report
}

\author{
Takayuki Ando ${ }^{1 *}$, Takahiko Nakajima ${ }^{2}$, Rei Fukuda ${ }^{3}$, Keiko Nomura $^{4}$, Yo Niida ${ }^{5}$, Miho Sakumura ${ }^{1}$, lori Motoo ${ }^{1}$, \\ Hiroshi Mihara', Sohachi Nanjo ${ }^{1}$, Shinya Kajiura' ${ }^{1}$, Haruka Fujinami', Shojo Hojo ${ }^{6}$, Tsutomu Fujii ${ }^{6}$ and \\ Ichiro Yasuda ${ }^{1}$
}

\begin{abstract}
Background: Constitutional mismatch repair deficiency (CMMRD) is an extremely rare autosomal recessive hereditary disease characterized by the absence of mismatch repair gene activity from birth, which results in brain tumors, colonic polyposis, gastrointestinal cancers, and lymphomas later in life. An aggressive approach, including colectomy or proctocolectomy, is recommended for the treatment of colorectal cancer. Additionally, partial colectomy with subsequent endoscopic surveillance may be an alternative strategy due to poor patient's condition, although there is no evidence of surveillance endoscopy after partial colectomy for CMMRD.

Case presentation: A 13-year-old male patient with a history of T-lymphoblastic lymphoma underwent total gastrointestinal endoscopy, which revealed rectal cancer, colorectal polyposis, and duodenal adenoma. Differential diagnosis included constitutional mismatch repair deficiency according to its scoring system and microsatellite instability, and subsequent germline mutation testing for mismatch repair genes confirmed the diagnosis of constitutional mismatch repair deficiency based on a homozygous mutation in mutS homolog 6 (MSH6). The patient and his family refused colectomy due to the high risk of malignancies other than colorectal cancer, which could require radical surgery. Therefore, the patient underwent low anterior resection of the rectosigmoid colon for rectal cancer and intensive surveillance endoscopy for the remaining colon polyposis. During the 3-year period after initial surgery, 130 polyps were removed and the number of polyps gradually decreased during 6-months interval surveillance endoscopies, although only one polyp was diagnosed as invasive adenocarcinoma (pT1).
\end{abstract}

Conclusions: Our experience of short surveillance endoscopy illustrates that this strategy might be one of options according to patient's condition.

Keywords: Colorectal polyposis, Constitutional mismatch repair deficiency, Surveillance endoscopy, Lynch syndrome, Case report

*Correspondence: taando33@gmail.com

${ }^{1}$ Third Department of Internal Medicine, University of Toyama, 2630 Sugitani, 930-0194 Toyama, Japan

Full list of author information is available at the end of the article

This article belongs to the Topical Collection: Colorectal cancer.

\section{Background}

Lynch syndrome is a cancer predisposition syndrome caused by heterozygous germline mutations in DNA mismatch repair (MMR) genes, including mutL homolog 1 (MLH1), mutS homolog 2 (MSH2), MSH6, PMS1 
homolog 2 (PMS2), and epithelial cell adhesion molecule $(E P C A M)$ [1-3]. Conversely, constitutional mismatch repair deficiency (CMMRD) is an extremely rare autosomal recessive hereditary disease. Individuals with biallelic MMR mutations develop gastrointestinal polyposis; early-onset brain, hematological, and gastrointestinal cancers; and neurofibromatosis 1-like phenotype including café au lait macules [4-6]. In a cohort of 24 individuals with CMMRD, the International Hereditary Biallelic Mismatch Repair Deficiency (BMMRD) Consortium reported that almost $80 \%$ of patients with CMMRD had gastrointestinal adenomas or cancers and that $60 \%$ of patients had non-gastrointestinal cancers including lymphoma, leukemia, and brain cancer [7]. Therefore, treatment strategies for colorectal cancer include careful evaluation of the entire gastrointestinal tract and consideration of the patient's general condition and risk of other neoplasms, although colectomy or proctocolectomy is recommended ${ }^{4}$. If neither procedure can be performed due to the patient's condition, partial colectomy with subsequent endoscopic surveillance may be an alternative strategy [4]. However, the clinical course after partial colectomy remains unclear. Herein, we report the 3-year intensive endoscopic surveillance results after partial colectomy for early rectal cancer in a patient with CMMRD-associated multiple gastrointestinal tumors.

\section{Case presentation}

A 6-year-old boy was diagnosed with T-lymphoblastic lymphoma and received chemotherapy and radiotherapy; he achieved complete remission and underwent annual follow-up with positron emission tomography/computed tomography (CT) using 18-fluoro-2-deoxyglucose. At the age of 13 , he was referred to our department for further evaluation of a rectal tumor identified by positron emission tomography/CT.

Physical examination revealed several café au lait macules and multiple cutaneous hemangiomas. Abdominal enhanced CT revealed irregular rectal wall thickening without lymphadenopathy or distant metastases (Fig. 1A-C). Total colonoscopy and endoscopic biopsy revealed a $45-\mathrm{mm}$ sessile adenocarcinoma with a central depression in the rectosigmoid area and more than 100 adenomatous polyps, $2-15 \mathrm{~mm}$ in size, distributed throughout the colon and rectum (Fig. 2A, B). Additionally, one duodenal adenoma, $10 \mathrm{~mm}$ in size, was identified by esophagoduodenoscopy and capsule endoscopy. Serum levels of immunoglobulin G and G4 were 434 (normal, 870-1700) and <2.0 (normal, 11-121) mg/ $\mathrm{dL}$, respectively.

CMMRD was considered in the differential diagnosis based on these findings and the CMMRD scoring system, although the patient did not fulfill the Amsterdam criteria for Lynch syndrome (Fig. 1D) [8, 9]. Therefore, testing after obtaining informed consent revealed the rectal cancer harbored high microsatellite instability. After obtaining further written informed consent, subsequent genetic testing performed for hereditary colorectal cancer syndromes, including those associated with mismatch repair genes (MLH1, MSH2, PMS2, and MSH6), adenomatous polyposis coli, and mutYH-associated polyposis revealed one homozygous frame shift mutation in MSH6 (NM_000179.2; c.3261del p.Phe1088SerfsTer2), which was reported as pathogenic (ClinVar accession VCV000089363.14, https://www.ncbi.nlm.nih.gov/clinv ar/, last accessed May 15, 2021), confirming the diagnosis of CMMRD (Fig. 2 A). Genetic testing showed that the patient's mother and father were heterozygous carriers of the MSH6 c.3261del mutation, leading to the diagnosis of Lynch syndrome based on the same germline mutation in both parents (Fig. 3A, B). Both parents had normal findings by colonoscopy and esophagoduodenoscopy.

The patient and his parents were carefully and repeatedly informed about the risks and benefits of colectomy and proctocolectomy for rectal cancer and colorectal polyposis, which they declined because of the high risk of small intestinal and non-gastrointestinal cancers in future. Therefore, the patient underwent low anterior resection (LAR) of the rectosigmoid colon for rectal cancer and surveillance endoscopy was planned for the remaining colon polyposis and duodenal adenoma. Histopathologically, the excised rectal mass was an intramucosal, moderately differentiated tubular adenocarcinoma (pTis) in tubulovillous adenoma without lymph node metastasis. The patient was diagnosed with Stage I rectal cancer according to the Tumor-Node-Metastasis staging system (Fig. 2C-F). After surgery, colonoscopy was planned with the following goals: (1) polypectomy every 4-6 months until only polyps sized $<4 \mathrm{~mm}$ remained; (2) histological evaluation of polyps sized $>10 \mathrm{~mm}$ and polyps sized $<10 \mathrm{~mm}$ with suspicion of cancer based on endoscopic appearance [10].

(See figure on next page.)

Fig. 1 Findings of computed tomography scan, physical examination, and CMMRD scoring system. A Abdominal computed tomography image showing rectal wall thickening without lymphadenopathy (white arrowheads). B, C On physical examination, several café au lait macules and multiple cutaneous hemangiomas on back and right leg, respectively, are visible. D The patient had scores of 5 and 14 points, before and after genetic testing, respectively, according to the CMMRD scoring system. $\square$, criteria fulfilled before genetic testing; $\boldsymbol{\diamond}$, criteria fulfilled after genetic testing; $\square$, unfulfilled criteria; CMMRD, constitutional mismatch repair deficiency 

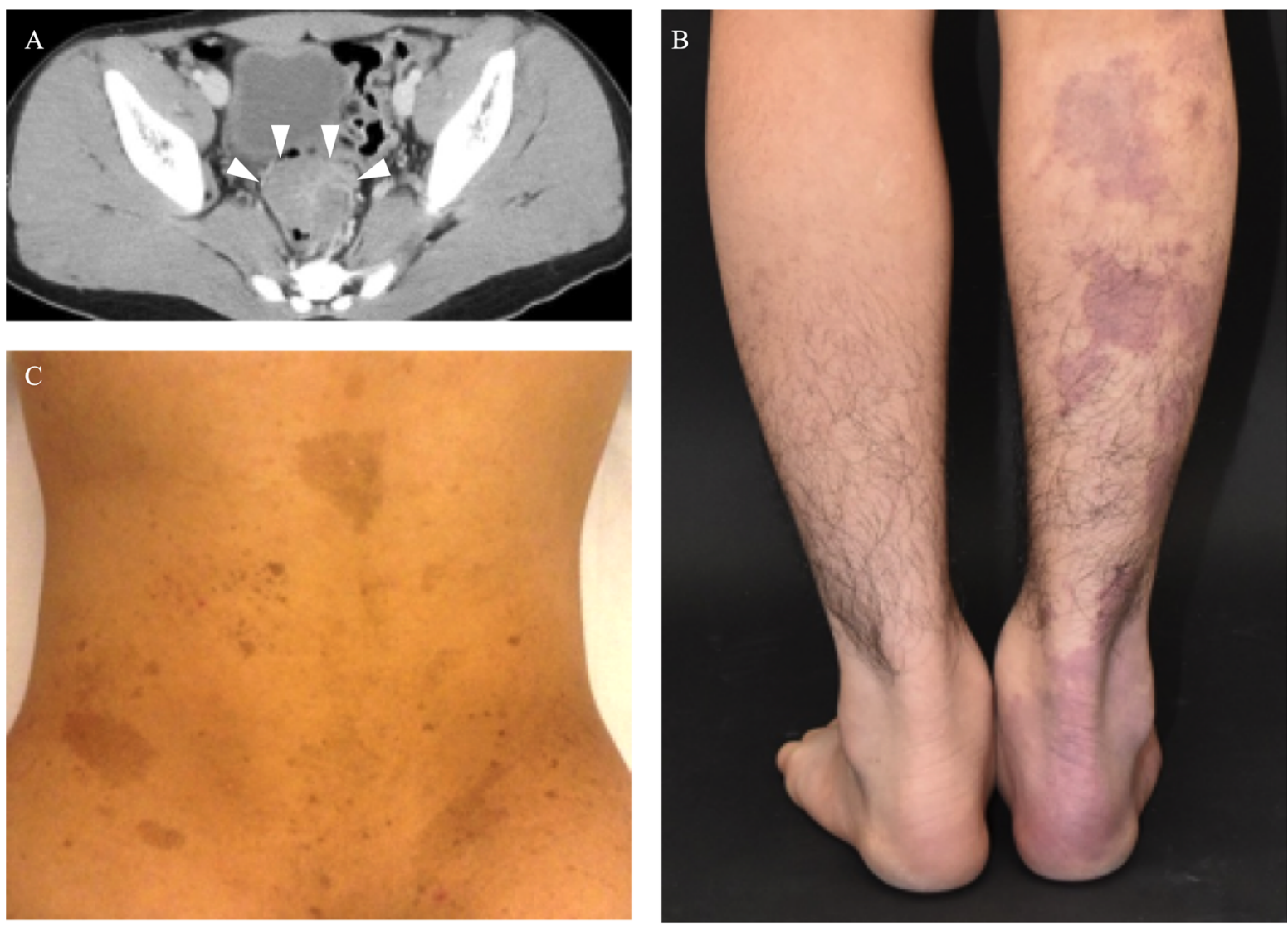

$\mathrm{D}$

CMMRD scoring system for a clinical suspicion of CMMRD in cancer patients

Indication for CMMRD testing in cancer patients

3 points or more

Malignancies/premalignancies: one is mandatory; if more than one is present in the patient, add the points

- Carcinoma from the LS spectrum at age $<25$ years

- Multiple bowel adenomas at age $<25$ years and absence of APC/MUTYH mutation(s) or a single high- 3 grade dysplasia adenoma at age $<25$ years

口 WHO grade III or IV glioma at age $<25$ years

- NHL of T-cell lineage or sPNET at age $<18$ years

- Any malignancy at age $<18$ years

Additional features: optional; if more than one of the following is present, add the points

- Clinical sign of NF1 and/or 2 hyperpigmented and/or hypopigmented skin alterations $>1 \mathrm{~cm}$ in the patient

- Diagnosis of LS in a first-degree or second-degree relative

- Carcinoma from LS spectruma before the age of 60 in first-degree, second-degree, or third-degree relative

- A sibling with carcinoma from the LS spectruma, high-grade glioma, sPNET, or NHL

口 A sibling with any type of childhood malignancy

口 Multiple pilomatricomas in the patient

․ One pilomatricoma in the patient

․ Agenesis of the corpus callosum or non-therapy-induced cavernoma in the patient

․ Consanguineous parents

- Deficiency/reduced levels of $\operatorname{IgG} 2 / 4$ and/or IgA

CMMRD, constitutional mismatch repair-deficiency; LS, lynch syndrome; WHO, World Health Organization; sPNET, supratentorial primitive neuroectodermal tumors; NHL, Non Hodgkins lymphoma

Fig. 1 (See legend on previous page.) 

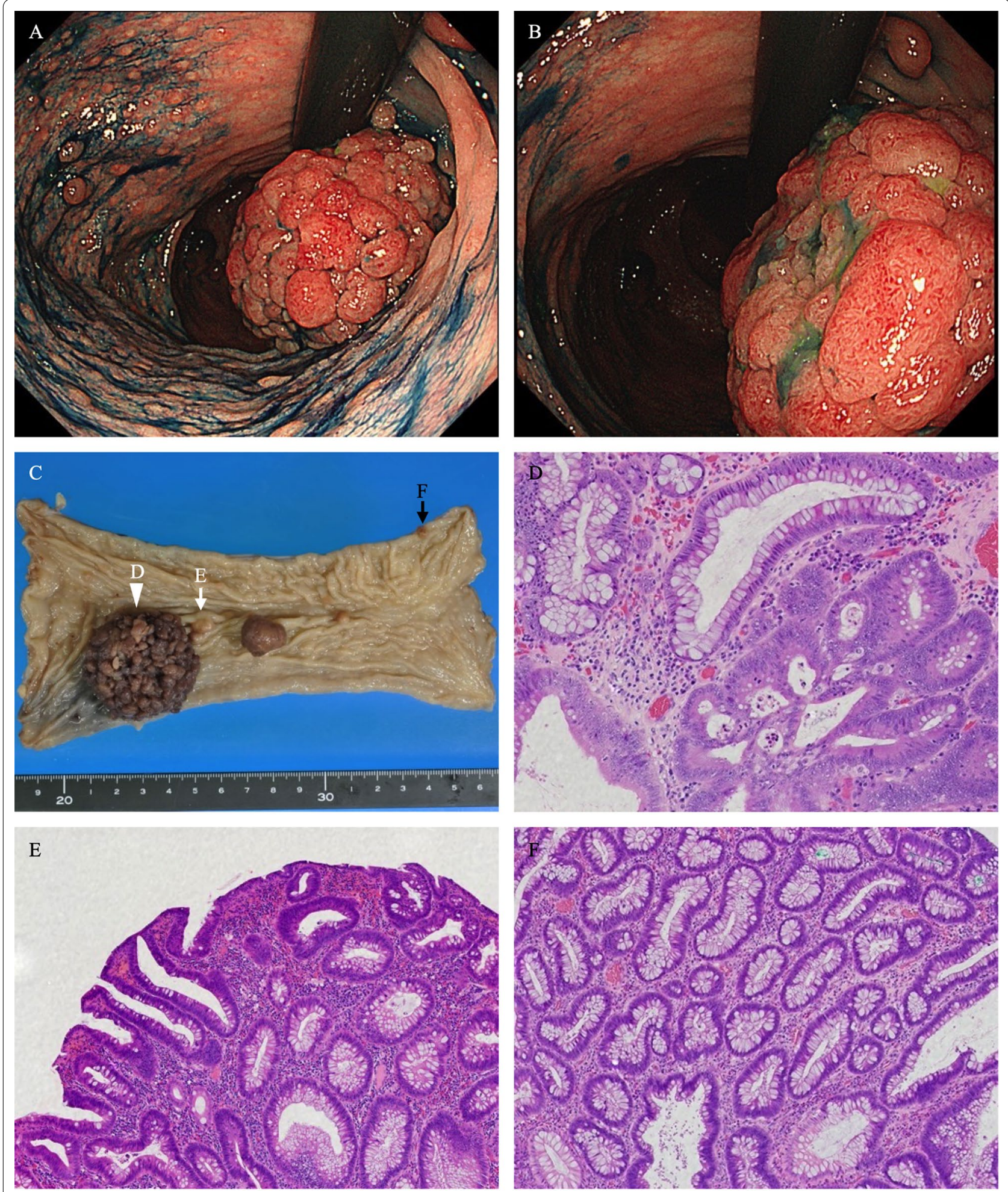

Fig. 2 Colonoscopic and pathological findings of colorectal polyps. A, B Colonoscopy showing a sessile polyp with a central depression in the rectosigmoid area and multiple polyps. C Gross image of the resected rectosigmoid colon. A total of 13 polyps, with maximum diameters of up to $45 \mathrm{~mm}$, are found. D Microscopic view of the largest polyp (white arrowhead in B). Intramucosal adenocarcinoma (pT1) with complex cribriform architecture in adenoma. E, F Microscopic view of other polyps (black and white arrows in C). Low-grade tubular adenoma 
During the first colonoscopy after surgery, two polyps were pathologically diagnosed as intramucosal adenocarcinoma (pTis) in adenoma. However, in the third colonoscopy, one polyp, sized $8 \mathrm{~mm}$, in descending colon was diagnosed as invasive adenocarcinoma without lymphovascular invasion $(>1000 \mu \mathrm{m}, \mathrm{pT} 1)$. The patient refused the recommended additional surgery including colectomy. Subsequently, surveillance endoscopy and CT examination were continued, and lymph node and distant metastases were not present at last follow-up at three years after initial surgery. During the 3-year followup period with short-interval surveillance colonoscopy, 130 colon polyps were removed without adverse events, and the number of detected polyps gradually decreased (Table 1). The duodenal adenoma was treated with endoscopic mucosal resection after LAR. Until the last follow-up, the subsequently performed annual esophagoduodenoscopy and capsule endoscopy led to the identification of three duodenal adenomas, sized $<5 \mathrm{~mm}$, which were removed.

\section{Discussion and conclusions}

Recent studies suggest that $>50 \%, 40 \%$, and $30 \%$ of patients with CMMRD develop malignant brain tumors, gastrointestinal tumors, and hematological malignancies, all during childhood, reflecting the generally poor prognosis of CMMRD [4]. The most frequent CMMRD-associated cancers are brain glioma diagnosed at 9.5 years of age, non-Hodgkin's lymphoma diagnosed at 5 years of age, and colorectal cancer diagnosed at 16 years of age [11]. Besides very high tumor risks, CMMRD phenotypes are often characterized by the presence of signs reminiscent of neurofibromatosis type 1 [8]. The present 13-yearold patient with CMMRD and history of T-lymphoblastic lymphoma is a case of colon polyposis caused by biallelic germline mutation in an MMR gene.

The management of colon cancer in patients with CMMRD is based on the frequency of synchronous or metachronous gastrointestinal and non-gastrointestinal cancers. The International BMMRD Consortium reported that the approximate frequencies of synchronous and metachronous colorectal cancers were 20 and $50 \%$, respectively [7]. Therefore, an aggressive approach, including colectomy with ileorectal anastomosis or proctocolectomy and construction of an ileal pouch-anal anastomosis, is recommended for colon polyposis in
CMMRD patients [5]. Moreover, close monitoring of the rectum with endoscopy every 6 or 12 months is crucial after ileorectal anastomosis. However, metachronous non-colorectal cancers are frequent in patients with CMMRD [12]. Among eight patients with CMMRD and colorectal cancer, small intestinal and non-gastrointestinal cancers were diagnosed after the treatment of colorectal cancer in one and three patients, respectively [7]. Moreover, the cancer spectrum is reported to be related to specific MMR gene mutations. MSH6 and/or PMS2 mutations lead to cancers within ten years of life, and $34 \%$ of patients with MSH6 mutations develop a second metachronous malignancy. The current patient and his parents refused colectomy after considering the high risk of metachronous cancers including non-gastrointestinal cancers.

In the present patient, the treatment strategy for colon polyposis was based on the endoscopic treatment for familial adenomatous polyposis (FAP), in which colectomy is a standard approach to prevent colorectal cancer [13]. However, colectomy is also associated with morbidity and mortality and removal of the large intestine affects quality of life $[14,15]$. Therefore, the efficacy and safety of endoscopic management for colon clearance was considered in the current patient. In a study of patients with FAP refusing surgery, invasive colorectal cancer was not observed during a median follow-up of 5.1 years and there were no complications, suggesting that endoscopic management might prevent cancer development in patients with FAP $[10,16]$. On the other hand, partial colectomy with subsequent regular surveillance colonoscopy is recommended in patients with Lynch syndrome and colorectal cancer, although the appropriate interval of surveillance colonoscopy after partial colectomy remains unclear [17]. However, colonoscopy performed in 6-month intervals was occasionally insufficient to detect endoscopically resectable tumors in some patients with high risk Lynch syndrome. Indeed, the present patient was diagnosed with an invasive cancer in descending colon during third colonoscopy after LAR. Additional surgery should be done in cases of endoscopically resected $\mathrm{T} 1$ cancer with positive vertical margin, although the relapse ratio of approximately $3.4 \%$ is relatively low [18]. Therefore, our strategy should be considered when colectomy is not appropriate due to patient's condition.

\footnotetext{
(See figure on next page.)

Fig. 3 Family pedigree and genetic testing. A Proband's pedigree revealed colon cancer findings in their seventies and eighties, respectively. B Sanger sequencing confirmed a homozygous mutation in MSH6 exon 5. The deletion of $\mathrm{C}$ at 3261 results in an amino acid change from CCC to CCT and a change in amino acid 1089 to the stop codon (TAG). The parents of the patient are carriers of the MSH6c.3261 delC mutation, MSH6, mutS homolog 6
} 


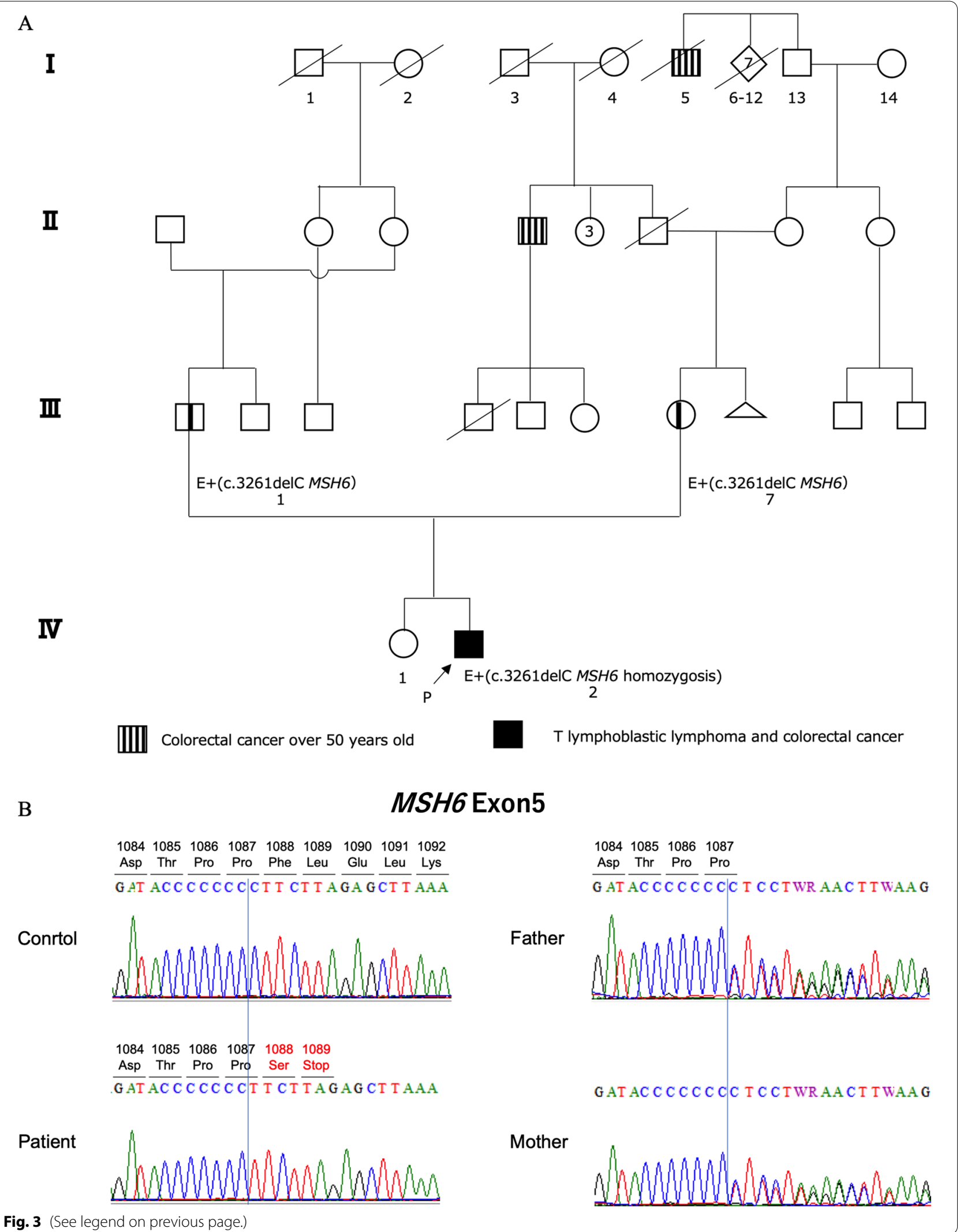


Table 1 Clinicopathological characteristics of colon polyps treated during surveillance colonoscopy after surgery

\begin{tabular}{|c|c|c|c|c|c|c|c|c|c|}
\hline \multirow[t]{2}{*}{ Session } & \multirow{2}{*}{$\begin{array}{l}\text { Months } \\
\text { after } \\
\text { surgery }\end{array}$} & \multirow{2}{*}{$\begin{array}{l}\text { Total number } \\
\text { of colon polyps } \\
\text { removed }\end{array}$} & \multirow{2}{*}{$\begin{array}{l}\text { Carcinoma } \\
\text { diagnosis }\end{array}$} & \multicolumn{6}{|c|}{ Carcinoma characteristics } \\
\hline & & & & Location & Growth type & Size $(\mathrm{mm})$ & pT stage* & $\begin{array}{l}\text { Horizontal } \\
\text { margin }\end{array}$ & Vertical margin \\
\hline \multirow[t]{2}{*}{1} & 2 & 22 & Yes & $S$ & Polypoid & 20 & pTis & $(-)$ & $(-)$ \\
\hline & & & & $\mathrm{R}$ & Polypoid & 17 & pTis & $(-)$ & $(-)$ \\
\hline 2 & 7 & 42 & No & & & & & & \\
\hline 3 & 12 & 23 & Yes & D & LST-NG & 8 & pT1 & (ND) & (ND) \\
\hline 4 & 18 & 12 & No & & & & & & \\
\hline 5 & 24 & 12 & No & & & & & & \\
\hline 6 & 30 & 19 & No & & & & & & \\
\hline
\end{tabular}

$S$ sigmoid colon, $R$ rectum, $D$ descending colon, LST-NG laterally spreading tumor non-granular type, ND not determined

*Based on classification system by the Union for International Cancer Control

Recent studies analyzing the association between tumor genetics and clinical spectrum should lead to the development of appropriate treatment strategies in patients with CMMRD [19]. In a study utilizing nextgeneration sequencing of 17 high-grade brain tumors in patients with CMMRD, the tumors exhibited massive numbers of substitution mutations (average, 7911 coding mutations; 249 mutations $/ \mathrm{Mb}$ ), which were higher than that observed in tumors of patients without CMMRD (0.61 mutations/Mb); the CMMRD-associated tumors were termed ultra-hypermutated cancers [20]. Moreover, these cancers acquired driver mutations in DNA polymerase $\varepsilon(P O L E)$ or $\delta$ (POLD1), which appeared to result in the loss of replication fidelity and a high mutation rate [21]. Gastrointestinal polyps without POLE and POLD1 mutations in patients with CMMRD did not exhibit higher mutational loads. Another study reported differences in the prevalence rates of hematological, brain, and Lynch syndrome-associated cancers among patients with CMMRD harboring MLH1/MSH2, MSH6, and PMS2 mutations ${ }^{6}$. These results should contribute to the adjustment of treatment modalities, offering surveillance strategies for second malignancies and appropriate counseling of the entire family.

In the present patient with CMMRD and colon polyposis, intensive surveillance endoscopy for multiple gastrointestinal tumors enabled the reduction in the number of lesions. The standard of care should be colectomy or protocolectomy for colorectal polyposis in patients with CMMRD. However, our experience of short surveillance endoscopy illustrates that our strategy might be one of options according to patient's condition.

\section{Acknowledgements}

Not applicable.

\section{Authors' contributions}

$T A, R F, K N, M S, I M, H M, S N, S K, H F, S H$ managed the patient and family and performed surveillance endoscopy. TN evaluated histology of resected specimens. YN performed mutational analysis. TA, YN, TF and IY wrote and edited the manuscript. All authors read and approved the final manuscript.

\section{Funding}

There is no funding for the study.

Availability of data and materials

The datasets used and/or analyzed during this study are included in this paper and shall be available from the corresponding author upon request.

\section{Declarations}

Ethics approval and consent to participate

This study was approved by the medical ethics committee of the Toyama University Hospital (E2021001).

\section{Consent for publication}

Written informed consent was obtained from the patient for publication of this Case report and any accompanying images.

\section{Competing interests}

The authors declare that they have no competing interests.

\section{Author details}

${ }^{1}$ Third Department of Internal Medicine, University of Toyama, 2630 Sugitani, 930-0194 Toyama, Japan. ${ }^{2}$ Department of Diagnostic Pathology, Graduate School of Medicine and Pharmaceutical Sciences, University of Toyama, Toyama, Japan. ${ }^{3}$ Department of Clinical Genetics, Toyama University Hospital, Toyama, Japan. ${ }^{4}$ Department of Pediatrics, University of Toyama, Toyama, Toyama, Japan. ${ }^{5}$ Division of Genomic Medicine, Department of Advanced Medicine, Medical Research Institute, Kanazawa Medical University, Uchinada, Ishikawa, Japan. ${ }^{6}$ Department of Surgery and Science, Faculty of Medicine, Academic Assembly, University of Toyama, Toyama, Japan.

Received: 23 May 2021 Accepted: 13 August 2021

Published online: 23 August 2021

\section{References} CMMRD: Constitutional mismatch repair deficiency; CT: Computed tomogra-
phy; LAR: Low anterior resection; FAP: Familial adenomatous polyposis.
1. Douglas JA, Gruber SB, Meister KA, Bonner J, Watson P, Krush AJ, Lynch HT. History and molecular genetics of Lynch syndrome in family G: a century later. JAMA. 2005;294(17):2195-202. 
2. Li GM. Mechanisms and functions of DNA mismatch repair. Cell Res. 2008;18(1):85-98.

3. Lynch HT, Snyder CL, Shaw TG, Heinen CD, Hitchins MP. Milestones of Lynch syndrome: 1895-2015. Nat Rev Cancer. 2015;15(3):181-94.

4. Vasen HF, Ghorbanoghli Z, Bourdeaut F, Cabaret O, Caron O, Duval A, EntzWerle N, Goldberg Y, Ilencikova D, Kratz CP, et al. Guidelines for surveillance of individuals with constitutional mismatch repair-deficiency proposed by the European Consortium "Care for CMMR-D" (C4CMMR-D). J Med Genet. 2014:51(5):283-93.

5. Durno C, Boland CR, Cohen S, Dominitz JA, Giardiello FM, Johnson DA, Kaltenbach T, Levin TR, Lieberman D, Robertson DJ, et al. Recommendations on surveillance and management of biallelic mismatch repair deficiency (BMMRD) syndrome: a consensus statement by the US multi-society task force on colorectal cancer. J Pediatr Gastroenterol Nutr. 2017;64(5):836-43.

6. Bakry D, Aronson M, Durno C, Rimawi H, Farah R, Alharbi QK, Alharbi M, Shamvil A, Ben-Shachar S, Mistry M, et al. Genetic and clinical determinants of constitutional mismatch repair deficiency syndrome: report from the constitutional mismatch repair deficiency consortium. Eur J Cancer. 2014;50(5):987-96.

7. Aronson M, Gallinger S, Cohen Z, Cohen S, Dvir R, Elhasid R, Baris HN, Kariv R, Druker H, Chan $\mathrm{H}$, et al. Gastrointestinal findings in the largest series of patients with hereditary biallelic mismatch repair deficiency syndrome: report from the international consortium. Am J Gastroenterol. 2016;111(2):275-84

8. Wimmer K, Kratz CP, Vasen HF, Caron O, Colas C, Entz-Werle N, Gerdes AM, Goldberg Y, llencikova D, Muleris M, et al. Diagnostic criteria for constitutional mismatch repair deficiency syndrome: suggestions of the European consortium 'care for CMMRD' (C4CMMRD). J Med Genet. 2014;51(6):355-65.

9. Hampel H, Frankel WL, Martin E, Arnold M, Khanduja K, Kuebler P, Nakagawa H, Sotamaa K, Prior TW, Westman J, et al. Screening for the Lynch syndrome (hereditary nonpolyposis colorectal cancer). N Engl J Med. 2005;352(18):1851-60.

10. Ishikawa H, Mutoh M, Iwama T, Suzuki S, Abe T, Takeuchi Y, Nakamura T, Ezoe Y, Fujii G, Wakabayashi K, et al. Endoscopic management of familial adenomatous polyposis in patients refusing colectomy. Endoscopy. 2016;48(1):51-5.

11. Wimmer K, Etzler J. Constitutional mismatch repair-deficiency syndrome: have we so far seen only the tip of an iceberg? Hum Genet. 2008;124(2):105-22.

12. Soplepmann J, Laidre P. Teenage colorectal polyposis and cancer may be caused by constitutional mismatch repair deficiency (CMMRD). Acta Oncol. 2016;55(12):1503-5.
13. Hassan C, Antonelli G, Dumonceau JM, Regula J, Bretthauer M, Chaussade S, Dekker E, Ferlitsch M, Gimeno-Garcia A, Jover R, et al. Post-polypectomy colonoscopy surveillance: European Society of Gastrointestinal Endoscopy (ESGE) Guideline: update 2020. Endoscopy. 2020;52(8):687-700.

14. Moslein G. Surgical considerations in FAP-related pouch surgery: could we do better? Fam Cancer. 2016;15(3):457-66.

15. Van Duijvendijk P, Slors JF, Taat CW, Oosterveld P, Sprangers MA, Obertop H, Vasen HF. Quality of life after total colectomy with ileorectal anastomosis or proctocolectomy and ileal pouch-anal anastomosis for familial adenomatous polyposis. Br J Surg. 2000;87(5):590-6.

16. Tanaka S, Saitoh Y, Matsuda T, Igarashi M, Matsumoto T, Iwao Y, Suzuki Y, Nozaki R, Sugai T, Oka S, et al. Evidence-based clinical practice guidelines for management of colorectal polyps. J Gastroenterol. 2021;56(4):323-35.

17. Ishida H, Yamaguchi T, Tanakaya K, Akagi K, Inoue Y, Kumamoto K, Shimodaira H, Sekine S, Tanaka T, Chino A, et al. Japanese Society for Cancer of the Colon and Rectum (JSCCR) guidelines 2016 for the clinical practice of hereditary colorectal cancer (translated version). J Anus Rectum Colon. 2018;2(Suppl I):1-51.

18. Saitoh Y, Inaba Y, Sasaki T, Sugiyama R, Sukegawa R, Fujiya M. Management of colorectal T1 carcinoma treated by endoscopic resection. Dig Endosc. 2016;28(3):324-9.

19. Lorans M, Dow E, Macrae FA, Winship IM, Buchanan DD. Update on hereditary colorectal cancer: improving the clinical utility of multigene panel testing. Clin Colorectal Cancer. 2018;17(2):e293-305.

20. Shlien A, Campbell BB, de Borja R, Alexandrov LB, Merico D, Wedge D, Van Loo P, Tarpey PS, Coupland P, Behjati S, et al. Combined hereditary and somatic mutations of replication error repair genes result in rapid onset of ultra-hypermutated cancers. Nat Genet. 2015;47(3):257-62.

21. Ghodgaonkar MM, Kehl P, Ventura I, Hu L, Bignami M, Jiricny J. Phenotypic characterization of missense polymerase-delta mutations using an inducible protein-replacement system. Nat Commun. 2014;5:4990.

\section{Publisher's Note}

Springer Nature remains neutral with regard to jurisdictional claims in published maps and institutional affiliations.
Ready to submit your research? Choose BMC and benefit from:

- fast, convenient online submission

- thorough peer review by experienced researchers in your field

- rapid publication on acceptance

- support for research data, including large and complex data types

- gold Open Access which fosters wider collaboration and increased citations

- maximum visibility for your research: over $100 \mathrm{M}$ website views per year

At BMC, research is always in progress.

Learn more biomedcentral.com/submissions 